\title{
Slow State Transitions of Sustained Neural Oscillations by Activity-Dependent Modulation of Intrinsic Excitability
}

\author{
Flavio Fröhlich, ${ }^{1,2}$ Maxim Bazhenov, ${ }^{1}$ Igor Timofeev, ${ }^{3}$ Mircea Steriade, ${ }^{3}$ and Terrence J. Sejnowski ${ }^{1,2}$ \\ ${ }^{1}$ The Salk Institute for Biological Studies, Computational Neurobiology Laboratory and Howard Hughes Medical Institute, La Jolla, California 92037, \\ ${ }^{2}$ Division of Biological Sciences, Section of Neurobiology, University of California San Diego, La Jolla, California 92093, and ${ }^{3}$ Laboratory of \\ Neurophysiology, School of Medicine, Laval University, Quebec, Canada G1K 7P4
}

\begin{abstract}
Little is known about the dynamics and mechanisms of transitions between tonic firing and bursting in cortical networks. Here, we use a computational model of a neocortical circuit with extracellular potassium dynamics to show that activity-dependent modulation of intrinsic excitability can lead to sustained oscillations with slow transitions between two distinct firing modes: fast run (tonic spiking or fast bursts with few spikes) and slow bursting. These transitions are caused by a bistability with hysteresis in a pyramidal cell model. Balanced excitation and inhibition stabilizes a network of pyramidal cells and inhibitory interneurons in the bistable region and causes sustained periodic alternations between distinct oscillatory states. During spike-wave seizures, neocortical paroxysmal activity exhibits qualitatively similar slow transitions between fast run and bursting. We therefore predict that extracellular potassium dynamics can cause alternating episodes of fast and slow oscillatory states in both normal and epileptic neocortical networks.
\end{abstract}

Key words: neocortex; computational model; bistability; hysteresis; extracellular potassium concentration; paroxysmal activity

\section{Introduction}

Neural oscillations are a hallmark of cortical network dynamics (Buzsaki and Draguhn, 2004). Sustained oscillatory activity can be broadly classified as either tonic firing or bursting. Neurons in a number of brain structures including the thalamus (Jahnsen and Llinas, 1984a,b) and neocortex (McCormick et al., 1985; Connors and Gutnick, 1990) exhibit either tonic firing or bursting in a state-dependent way. One of the most dramatic examples of global transitions between bursting and tonic spiking regimens is the transition from slow-wave sleep to rapid eye movement sleep or waking in the thalamocortical system (Steriade et al., 1993, 2001; Timofeev et al., 2001; Steriade and McCarley, 2005). Slow transitions between a slow-wave state and a fast-wave state were also observed in the olfactory cortex (Murakami et al., 2005). Coexistence of bursting and tonic spiking regimens is not limited to vertebrates (Lechner et al., 1996; Turrigiano et al., 1996; Shilnikov et al., 2005). Different levels of synaptic excitatory drive, activation of intrinsic conductances by neuromodulation, and changes in the extracellular ionic environment control the state-dependent oscillatory regimen (McCormick, 1992; Gil et al., 1997; Steriade and McCarley, 2005). Many of these mechanisms modulating neural excitability are activitydependent themselves and therefore work in a feedback man-

Received Dec. 22, 2005; revised April 14, 2006; accepted April 21, 2006

This work was supported by the National Institutes of Health and the Canadian Institutes of Health Research. I.T. is a scholar of the Canadian Institutes of Health Research. We thank Justin Elstrott for helpful comments.

Correspondence should be addressed to Dr. Maxim Bazhenov, The Salk Institute for Biological Studies, 10010 North Torrey Pines Road, La Jolla, CA 92037. E-mail: bazhenov@salk.edu.

D01:10.1523/JNEUROSCI.5509-05.2006

Copyright $\odot 2006$ Society for Neuroscience $\quad$ 0270-6474/06/266153-10\$15.00/0 ner. However, the interaction between intrinsic or network oscillatory dynamics and activity-dependent feedback control mechanisms in cortical networks is poorly understood. In particular, little is known about how these mechanisms can lead to (1) sustained neural activity in the absence of external input and (2) slow transitions between different oscillatory regimens (Steriade, 2004).

Intrinsic excitability depends on the reversal potential for potassium-mediated currents, which is a function of extracellular potassium concentration $\left[\mathrm{K}^{+}\right]_{\mathrm{O}}$. Extracellular potassium accumulates during sustained neural activity (Moody et al., 1974; Heinemann et al., 1977; Amzica et al., 2002; Timofeev et al., 2002). In turn, elevated $\left[\mathrm{K}^{+}\right]_{\mathrm{o}}$ increases intrinsic excitability, leading to spontaneous neural activity (Rutecki et al., 1985; Traynelis and Dingledine, 1988). Thus, $\left[\mathrm{K}^{+}\right]_{\mathrm{o}}$ dynamics modulate intrinsic excitability in a positive-feedback manner. It is well established that $\left[\mathrm{K}^{+}\right]_{\mathrm{o}}$ increases during paroxysmal activity (Moody et al., 1974; Heinemann et al., 1977); however, whether elevated $\left[\mathrm{K}^{+}\right]_{\mathrm{o}}$ is the primary factor eliciting seizures or is a byproduct of increased firing remains unknown. Glia cells play an important role in the regulation of $\left[\mathrm{K}^{+}\right]_{\mathrm{o}}$ by effectively acting as a potassium buffer (Kuffler et al., 1966; Orkand et al., 1966; Kofuji and Newman, 2004).

Here, in a realistic neocortical network model with potassium dynamics (Bazhenov et al., 2004), we investigate the complex cellular and network behavior caused by activity-dependent changes in extracellular potassium concentration. We show that a model of neocortical circuitry that includes the interaction between extracellular ion concentration and intrinsic excitability exhibits slow state transitions between two distinct oscillatory firing modes (tonic spiking and bursting) that have been observed in vivo but still lack theoretical explanations. 


\section{Materials and Methods}

Computational models. We used a mathematical model of a cortical network consisting of cortical pyramidal (PY) cells and inhibitory interneurons (INs) to study the effect of extracellular potassium dynamics on oscillatory firing regimens. Each model neuron (Mainen and Sejnowski, 1996; Bazhenov et al., 2004) incorporated both intrinsic and synaptic currents and was composed of an axosomatic compartment with membrane voltage $V_{\mathrm{S}}$ governed by the following:

$$
g\left(V_{\mathrm{S}}-V_{\mathrm{D}}\right)=-I_{\mathrm{S}}^{\mathrm{int}},
$$

and a dendritic compartment with membrane voltage $V_{\mathrm{D}}$ governed by the following:

$$
C_{\mathrm{m}} \mathrm{d} V_{\mathrm{D}} / \mathrm{d} t=-g_{\mathrm{L}}\left(V_{\mathrm{D}}-E_{\mathrm{L}}\right)-g\left(V_{\mathrm{D}}-V_{\mathrm{S}}\right)-I_{\mathrm{D}}^{\mathrm{int}}-I^{\text {syn }},
$$

where $g$ is the coupling conductance, $I_{\mathrm{S}}{ }^{\text {int }}$ and $I_{\mathrm{D}}{ }^{\text {int }}$ are the intrinsic currents in the two compartments, $C_{\mathrm{m}}$ is the membrane capacitance, and $g_{\mathrm{L}}$ and $E_{\mathrm{L}}$ are the conductance and reversal potential of the leak current, respectively. As in previous studies (Mainen and Sejnowski, 1996), we have omitted the axosomatic capacitance because axosomatic currents are sufficiently strong to change the somatic membrane voltage almost immediately. Assuming these very fast dynamics to be instantaneous by setting the somatic conductance to zero permitted the use of a larger integration step size, resulting in increased computational efficiency. The ratio of dendritic to axosomatic area $r$ was chosen to mimic a regular spiking neuron $(r=165)$ for PY and a fast spiking neuron $(r=50)$ for IN. Both active and passive biophysical mechanisms regulate potassium in the extracellular space. In the model, $\left[\mathrm{K}^{+}\right]_{\mathrm{o}}$ was continuously computed and the reversal potential for channels permeable to potassium updated accordingly. We studied the behavior of a single PY cell, a small globally connected network, and a larger one-dimensional two-layer (PY and IN) network. To investigate the effects of changes in $\left[\mathrm{K}^{+}\right]_{\mathrm{o}}$ on the firing behavior we explicitly controlled and varied $\left[\mathrm{K}^{+}\right]_{\mathrm{o}}$ in a subset of simulations (bifurcation analysis).

Intrinsic currents. Intrinsic ionic currents were mediated by a set of Hodgkin-Huxley type conductances. Fast inactivating $\mathrm{Na}^{+}$channels (high and low density in axosomatic and dendritic compartment, respectively) and fast delayed rectifier $\mathrm{K}^{+}$channels (axosomatic compartment) formed the basis of action potential generation. Further, persistent sodium conductance $G_{\mathrm{NaP}}$, slow voltage-gated $\mathrm{K}^{+}$conductance $G_{\mathrm{Km}}$, slow calcium-activated $\mathrm{K}^{+}$conductance $G_{\mathrm{KCa}}$, high-threshold $\mathrm{Ca}^{2+}$ conductance $G_{\mathrm{Ca}}$ and hyperpolarization-activated depolarizing conductance $G_{\mathrm{h}}$ were included in the dendritic compartment and $\mathrm{K}^{+}$leak conductance $G_{\mathrm{L}}$ was introduced in both axosomatic and dendritic compartments (Timofeev et al., 2000; Bazhenov et al., 2004). In a previous study (Bazhenov et al., 2004), many of these conductances were systematically varied to establish model robustness for parameter variations. The relative balance of intrinsic currents was altered by varying the maximal conductances. Here, we considered $G_{\mathrm{Ca}}=0.012-0.018 \mathrm{mS} / \mathrm{cm}^{2}, G_{\mathrm{KCa}}=$ $1.5-3.5 \mathrm{mS} / \mathrm{cm}^{2}, G_{\mathrm{NaP}}=3.0-4.0 \mathrm{mS} / \mathrm{cm}^{2}$, and $G_{\mathrm{h}}=0.0-0.1 \mathrm{mS} / \mathrm{cm}^{2}$.

Synaptic currents. Synaptic transmission was modeled by a first-order kinetic scheme of neurotransmitter binding and unbinding to postsynaptic receptors that was shown to well fit experimental data (Destexhe et al., 1994). We assumed neurotransmitter release time courses to be of rectangular shape, reducing the time course of the fraction of open receptors $[\mathrm{O}](t)$ after a presynaptic spike to a single exponential. All synaptic currents $I_{\text {syn }}$ were governed by the following:

$$
I_{\text {syn }}=g_{\text {syn }}[\mathrm{O}]\left(V-E_{\text {syn }}\right),
$$

where $g_{\text {syn }}$ is the maximal conductance $\left(g_{\mathrm{AMPA}(\mathrm{PY}-\mathrm{PY})}=0.20 \mu \mathrm{S}\right.$, $g_{\mathrm{NMDA}(\mathrm{PY}-\mathrm{PY})}=0.013 \mu \mathrm{S}, g_{\mathrm{AMPA}(\mathrm{PY}-\mathrm{IN})}=0.010 \mu \mathrm{S}, g_{\mathrm{NMDA}(\mathrm{PY}-\mathrm{IN})}=$ $\left.0.014 \mu \mathrm{S}, g_{\mathrm{GABA}(\mathrm{IN}-\mathrm{PY})}=0.05 \mu \mathrm{S}\right)$ and $E_{\mathrm{syn}}$ the reversal potential $\left(E_{\mathrm{AMPA}}\right.$ $\left.=0 \mathrm{mV}, E_{\mathrm{NMDA}}=0 \mathrm{mV}, \mathbf{E}_{\mathrm{GABA}_{\mathrm{A}}}=-80 \mathrm{mV}\right)$. Dependence of NMDA receptors on postsynaptic membrane voltage $V_{\text {post }}$ was modeled by $1 /\left(1+\exp \left(-\left(V_{\text {post }}-V_{\text {th }}\right) / \sigma\right)\right)$, with $V_{\text {th }}=-25 \mathrm{mV}$ and $\sigma=12.5 \mathrm{mV}$.

Short-term synaptic depression was described by a depression variable $D \leq 1$, which was multiplied with the maximal synaptic conductance (Tsodyks and Markram, 1997; Markram et al., 1998). D was adjusted with factor $r=0.93$ (7\% resources per action potential) from its previous value $D_{\mathrm{i}}$ after a presynaptic spike at time $t_{\mathrm{i}}$ with recovery time constant $\tau$ $=700 \mathrm{~ms}$ :

$$
D=1-\left(1-D_{\mathrm{i}} R\right) \exp \left(-\left(t-t_{\mathrm{i}}\right) / \tau\right) .
$$

Depression $D$ accounts for short-term use-dependent weakening of synaptic strength after subsequent stimulation and recovery thereof. To study the role of synaptic interaction, the balance of excitation and inhibition was altered in a subset of simulations by multiplying the maximal conductances of the corresponding synapses by the factors $0.8,0.9,1.1$, and 1.2 (scaling factors PY-PY for excitatory coupling between pyramidal cells and IN-PY for inhibitory coupling, respectively).

Potassium dynamics. $\left[\mathrm{K}^{+}\right]_{\mathrm{o}}$ was computed for extracellular volumes surrounding each cell. Our model of extracellular potassium dynamics followed a previously developed model (Bazhenov et al., 2004) in which parameters were systematically varied to study the robustness of the model. Processes affecting $\left[\mathrm{K}^{+}\right]_{\mathrm{o}}$ were channels permeable to $\mathrm{K}^{+}, \mathrm{K}^{+}$ pumps, and glial $\mathrm{K}^{+}$uptake (buffering) $G$ :

$$
\mathrm{d}\left[\mathrm{K}^{+}\right]_{\mathrm{o}(\mathrm{D}, \mathrm{S})} / \mathrm{d} t=(k / F d) I_{\Sigma \mathrm{K}}+G,
$$

where $k=10$ denotes a conversion factor, $F=96489 \mathrm{C} / \mathrm{mol}$, the Faraday constant, and $d$ the ratio of the volume of the extracellular compartment to the surface area. The total potassium current $I_{\Sigma \mathrm{K}}$ is the sum of all potassium currents (fast rectifying $I_{\mathrm{K}}$, calcium-activated $I_{\mathrm{KCa}}$, voltagedependent non-inactivating $I_{\mathrm{Km}}$, and leak current $I_{\mathrm{L}}$ ) and the current $I_{\mathrm{KPump}}$ mediated by $\mathrm{K}^{+}$pumps:

$$
I_{\Sigma \mathrm{K}}=I_{\mathrm{K}}+I_{\mathrm{KCa}}+I_{\mathrm{Km}}+I_{\mathrm{L}}+I_{\mathrm{KPump}} .
$$

The $\mathrm{K}^{+}$current $I_{\mathrm{KPump}}$ established by $\mathrm{K}^{+}$pumps was an inward current that had a sigmoidal dependence on the ratio of steady-state $\left[\mathrm{K}^{+}\right]_{\mathrm{o}(\mathrm{eq})}=$ $3.5 \mathrm{~mm}$ to current $\left[\mathrm{K}^{+}\right]_{\mathrm{o}}$ and saturated at $I_{\max }$, which was chosen to balance $\mathrm{K}^{+}$leak current (dendritic compartment $I_{\max }=5 \mu \mathrm{A} / \mathrm{cm}^{2}$, somatic compartment $I_{\max }=40 \mu \mathrm{A} / \mathrm{cm}^{2}$ ):

$$
I_{\mathrm{KPump}}=I_{\max } /\left(1+\left(\left[\mathrm{K}^{+}\right]_{\mathrm{o}(\mathrm{eq})} /\left[\mathrm{K}^{+}\right]_{\mathrm{o}}\right)\right)^{2} .
$$

Glial $\mathrm{K}^{+}$uptake current $G$ was modeled by a free buffer (total buffer $\left[\mathrm{B}_{\max }\right]=500 \mathrm{~mm}$ ) with concentration $[\mathrm{B}]$, which bound and unbound from $\mathrm{K}^{+}$with according on- and off-rates $k_{1}=0.008$ and $k_{2}=k_{1} /(1+$ $\left.\exp \left(\left(\left[\mathrm{K}^{+}\right]_{\mathrm{o}}-\left[\mathrm{K}^{+}\right]_{\mathrm{o}(\mathrm{th})}\right) /-1.15\right)\right)$ governed by first order kinetics:

$$
\begin{aligned}
\mathrm{d}[\mathrm{B}] / \mathrm{dt}=k_{1}\left([\mathrm{~B}]_{\max }-[\mathrm{B}]\right) & -k_{2}\left[\mathrm{~K}^{+}\right]_{\mathrm{o}}[\mathrm{B}], \\
G & =k_{1}\left([\mathrm{~B}]_{\max }-[\mathrm{B}]\right) / k_{1 \mathrm{~N}}-k_{2}\left[\mathrm{~K}^{+}\right]_{\mathrm{o}}[\mathrm{B}] .
\end{aligned}
$$

Threshold concentrations $\left[\mathrm{K}^{+}\right]_{\mathrm{o}(\mathrm{th})}(15 \mathrm{~mm}$ for somatic compartment, 9 $\mathrm{mm}$ for dendritic compartment) and $k_{1 \mathrm{~N}}=1.1$ were chosen such that $\mathrm{K}^{+}$ concentration equilibrated both for silent and tonic firing mode (Bazhenov et al., 2004).

Changes in $\left[\mathrm{K}^{+}\right]_{\mathrm{o}}$ changed the reversal potential for all conductances modeling ion channels permeable to $\mathrm{K}^{+}$. The Nernst equation described the reversal potential for pure $\mathrm{K}^{+}$conductances as follows:

$$
E_{\mathrm{K}}=26.64 \mathrm{mV} \ln \left(\left[\mathrm{K}^{+}\right]_{\mathrm{o}} /\left[\mathrm{K}^{+}\right]_{\mathrm{i}}\right) .
$$

The reversal potential for $G_{\mathrm{h}}$ and $G_{\mathrm{L}}$, which are ion channels permeable to several ion types, were updated according to the Goldman-HodgkinKatz equation, taking into account the different ionic concentrations $\left(\left[\mathrm{Na}^{+}\right]_{\mathrm{o}}=130 \mathrm{~mm},\left[\mathrm{Na}^{+}\right]_{\mathrm{i}}=20 \mathrm{~mm},\left[\mathrm{Cl}^{-}\right]_{\mathrm{o}}=130 \mathrm{~mm},\left[\mathrm{Cl}^{-}\right]_{\mathrm{i}}=8 \mathrm{~mm}\right)$ and degrees of permeability:

$$
E_{\mathrm{h}}=26.64 \mathrm{mV} \ln \left(\left[\mathrm{K}^{+}\right]_{\mathrm{o}}+0.2\left[\mathrm{Na}^{+}\right]_{\mathrm{o}}\right) /\left(\left[\mathrm{K}^{+}\right]_{\mathrm{i}}+0.2\left[\mathrm{Na}^{+}\right]_{\mathrm{i}}\right),
$$

$$
\begin{aligned}
E_{\mathrm{L}}=26.64 \mathrm{mV} \ln \left(\left[\mathrm{K}^{+}\right]_{\mathrm{o}}+0.085[\right. & \left.\left.\mathrm{Na}^{+}\right]_{\mathrm{o}}+0.1\left[\mathrm{Cl}^{-}\right]_{\mathrm{i}}\right) /\left(\left[\mathrm{K}^{+}\right]_{\mathrm{i}}\right. \\
& \left.+0.085\left[\mathrm{Na}^{+}\right]_{\mathrm{i}}+0.1\left[\mathrm{Cl}^{-}\right]_{\mathrm{o}}\right) .
\end{aligned}
$$

Calcium dynamics. Intracellular calcium concentration $\left[\mathrm{Ca}^{2+}\right]_{\mathrm{i}}$ was computed for the dendritic compartment in which the calcium-activated 
A

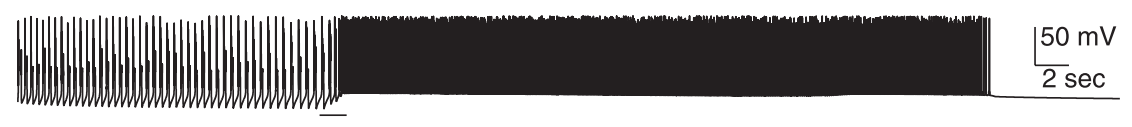

B
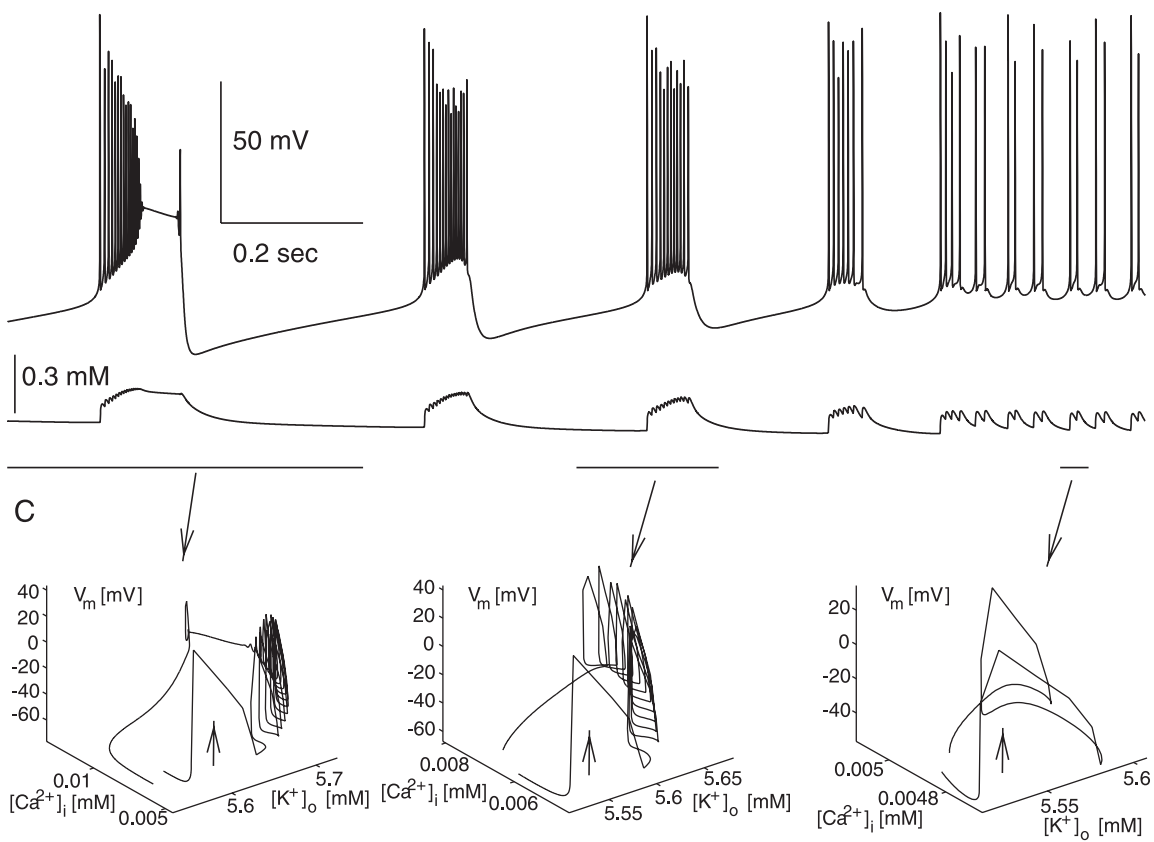

Figure 1. A, A single PY neuron exhibits bursting and then tonic firing after a brief increase in extracellular potassium concentration $\left(\left[\mathrm{K}^{+}\right]_{0}\right.$ ) before returning to rest. $\boldsymbol{B}$, Membrane voltage (top) and $\left[\mathrm{K}^{+}\right]_{0}$ (bottom) time courses for the time interval underlined in $\boldsymbol{A}$. The transition from bursting to tonic firing (spike doublets) at $\left[\mathrm{K}^{+}\right]_{0}=5.6 \mathrm{~mm}$ is shown. $\boldsymbol{C}$, Phase space plots $\left(\left[\mathrm{K}^{+}\right]_{0}\right.$ intracellular calcium $\left[\mathrm{Ca}^{2+}\right]_{i}$, and membrane voltage $\left.V_{\mathrm{m}}\right)$ for the three intervals underlined in $\boldsymbol{A}$. The arrow indicates the direction of time. A single burst with minor spike inactivation and after-hyperpolarization (left), a single burst without spike inactivation and reduced after-hyperpolarization (middle), and a spike doublet (right) are shown.

potassium channels were located. Calcium influx through highthreshold calcium channels was counteracted by exponential return to baseline concentration $\left[\mathrm{Ca}^{2+}\right]_{\mathrm{i}(\mathrm{eq})}$ modeling pumps extruding calcium from the cytosol:

$$
\mathrm{d}\left[\mathrm{Ca}^{2+}\right]_{\mathrm{i}} / \mathrm{dt}=k I_{\mathrm{Ca}} /(2 F)+\left(\left[\mathrm{Ca}^{2+}\right]_{\mathrm{i}(\mathrm{eq})}-\left[\mathrm{Ca}^{2+}\right]_{\mathrm{i}}\right) / \tau_{\mathrm{Ca}},
$$

where $k$ and $F$ are constants as described above, $\left[\mathrm{Ca}^{2+}\right]_{\mathrm{i}(\mathrm{eq})}=0.0001 \mathrm{~mm}$ is the equilibrium concentration, and $\tau_{\mathrm{Ca}}=500 \mathrm{~ms}$ is the recovery time constant.

Network topology. To dissociate the effect of synaptic coupling from the effect of intrinsic cellular responses to depolarized $\mathrm{K}^{+}$reversal potentials, we first studied the behavior of a single PY cell. Then, we used a small network of five PY cells and one IN with global connectivity where each PY cell was connected to every other PY cell by excitatory synapses (AMPA and NMDA). The IN received excitatory synapses from all PY cells (AMPA and NMDA) and projected back to all PY cells $\left(\mathrm{GABA}_{\mathrm{A}}\right)$. This compact network was a direct extension of the case of an isolated PY cell because no localized spatial patterns of activity arose and all neurons exhibited synchronous transitions in their firing regimens.

We studied the effect of changes in excitatory and inhibitory coupling by systematically varying the maximal conductance for AMPA and NMDA or GABA-mediated synaptic currents, respectively. We further used a larger network model composed of two one-dimensional layers formed by 60 PY cells and 15 IN, respectively. Each PY cell was connected to five neighboring PY cells on both sides, each PY cell connected to three neighboring INs, and each IN projected back to a total of eleven neighboring PY cells.

Bifurcation analysis. To study how extracellular $\mathrm{K}^{+}$concentration $\left[\mathrm{K}^{+}\right]_{\mathrm{o}}$ modulated neural activity, we held $\left[\mathrm{K}^{+}\right]_{\mathrm{o}}$ constant in a subset of the simulations to determine the firing behavior as a function of $\left[\mathrm{K}^{+}\right]_{\mathrm{o}}$.
This corresponds to opening the positive feedback loop between neural activity and $\left[\mathrm{K}^{+}\right]_{0}$. Such analysis provided useful predictions for the case where $\left[\mathrm{K}^{+}\right]_{\mathrm{o}}$ would freely evolve (i.e., closed feedback loop) because of the vastly different time-scales of the $\left[\mathrm{K}^{+}\right]_{\mathrm{o}}$ dynamics (slow) and the dynamics of the ion conductances mediating neural activity (fast). In other words, we used the slow/fast analysis technique for systems with widely differing time scales [geometric singular perturbation theory (Rinzel, 1985; Rinzel and Lee, 1987; Jones, 1995; Osinga and England, 2005)]. Extracellular $\mathrm{K}^{+}$concentration $\left[\mathrm{K}^{+}\right]_{\mathrm{o}}$, which exhibited very slow dynamics with time-scale corresponding to entire epochs of oscillatory firing at a given frequency, was treated as a parameter for bifurcation analysis. We used a combination of direct integration for different parameter values, continuation analysis [MATCONT software (Dhooge et al., 2003)], and Poincare cross sections (Kuznetsov, 2004) to trace and analyze bifurcations.

In vivo experiments. Experiments were conducted on cats anesthetized with ketaminexylazine anesthesia ( $10-15$ and $2-3 \mathrm{mg} / \mathrm{kg}$ i.m., respectively). The animals were paralyzed with gallamine triethiodide $(20 \mathrm{mg} / \mathrm{kg})$ after the electroencephalogram (EEG) showed typical signs of deep general anesthesia, essentially consisting of slow oscillation $(0.5-1 \mathrm{~Hz})$. Supplementary doses of the same anesthetics ( 5 and $1 \mathrm{mg} / \mathrm{kg})$ or ketamine $(5 \mathrm{mg} / \mathrm{kg})$ were administered at the slightest changes toward diminished amplitudes of slow waves. The cats were artificially ventilated with the control of endtidal $\mathrm{CO}_{2}$ at $3.5-3.7 \%$. Body temperature was maintained at $37-38^{\circ} \mathrm{C}$ and the heart rate was $\sim 90-100$ beats/min. For intracellular recordings, stability was ensured by the drainage of the cisterna magna, hip suspension, bilateral pneumothorax, and filling the hole made for recordings with a solution of $4 \%$ agar. At the end of experiments, the cats were given a lethal dose of pentobarbital ( $50 \mathrm{mg} / \mathrm{kg}$, i.v.). All experimental procedures were performed according to national guidelines and were approved by the Committee for Animal Care of Laval University.

Intracellular recordings from suprasylvian association areas 5 and 7 were performed using sharp glass micropipettes filled with a solution of $3 \mathrm{~m}$ potassium-acetate (KAc). Field potentials were recorded in the vicinity of impaled neurons. All electrical signals were sampled at $20 \mathrm{kHz}$ and digitally stored on Vision (Nicolet, Middleton, WI). Offline computer analysis of electrographic recordings was done with IgorPro software (WaveMetrics, Lake Oswego, OR).

\section{Results}

\section{Transition between slow bursting and tonic firing in a} single cell

A brief increase in $\left[\mathrm{K}^{+}\right]_{\mathrm{o}}$ was used to initiate activity in an otherwise silent PY neuron. An isolated PY cell model $\left(G_{\mathrm{Ca}}=0.015\right.$ $\mathrm{mS} / \mathrm{cm}^{2}, G_{\mathrm{h}}=0.1 \mathrm{mS} / \mathrm{cm}^{2}$ ) with a spatially limited extracellular compartment responded to a brief $\left[\mathrm{K}^{+}\right]_{\mathrm{o}}$ elevation with oscillatory firing before returning to rest. Although $\left[\mathrm{K}^{+}\right]_{\mathrm{o}}$ decreased to its resting value $(3.5 \mathrm{~mm})$, the PY cell exhibited several oscillatory modes: first, slow-bursting oscillations and then tonic firing (Fig. $1 A$, transition in $B)$. For significantly elevated $\left[\mathrm{K}^{+}\right]_{\mathrm{o}}>5.6 \mathrm{mM}$, bursts with spike inactivation, pronounced afterhyperpolarization, and strong calcium influx occurred (Fig. 1C, left, phase space plot of a single burst). Calcium influx during the depolarized state caused the calcium-activated potassium con- 
ductance to activate, which in turn mediated burst termination and subsequent after-hyperpolarization (supplemental Fig. 2, available at www.jneurosci.org as supplemental material). For $\left[\mathrm{K}^{+}\right]_{\mathrm{o}}=5.6 \mathrm{mM}$, however, there was a transition to bursts with reduced after-hyperpolarization and with minor spike inactivation (Fig. $1 C$, middle). For $\left[\mathrm{K}^{+}\right]_{\mathrm{o}}=5.5 \mathrm{~mm}$, the cell switched to tonic firing (Fig. $1 C$, right, spike doublets) before it eventually returned to rest. Both during slow bursting and tonic firing, potassium efflux occurred mainly through the fast delayed rectifier (41 and 43\% for bursting and tonic firing, respectively) and through the leak conductance (43 and 56\%, respectively). These oscillatory firing patterns for elevated $\left[\mathrm{K}^{+}\right]_{\mathrm{o}}$ are not a mere consequence of the depolarization of the neuron because an injected depolarizing current step caused only tonic firing with spike adaptation (supplemental Fig. 1, available at www.jneurosci.org as supplemental material).

Because $\left[\mathrm{K}^{+}\right]_{\mathrm{o}}$ changed on a very slow time-scale, we next treated $\left[\mathrm{K}^{+}\right]_{\mathrm{o}}$ as a parameter to determine the firing behavior of the cell as a function of $\left[\mathrm{K}^{+}\right]_{\mathrm{o}}$. Therefore, all of the mechanisms controlling $\left[\mathrm{K}^{+}\right]_{\mathrm{o}}$ evolution in our model were blocked and the neuron behavior was analyzed for different fixed values of $\left[\mathrm{K}^{+}\right]_{\mathrm{o}}$ within the physiological range. Specifically, we focused on the occurrence of different stable firing modes as a function of parameter $\left[\mathrm{K}^{+}\right]_{\mathrm{o}}$ (Fig. 2). For low $\left[\mathrm{K}^{+}\right]_{\mathrm{o}}$, the neuron was at rest (Fig. $2 \mathrm{~A}$, left). For increasing $\left[\mathrm{K}^{+}\right]_{\mathrm{o}}$, the resting potential became more depolarized as the driving force for potassium decreased. For $\left[\mathrm{K}^{+}\right]_{\mathrm{o}}=4.85 \mathrm{~mm}$, the neuron switched to tonic firing by means of a saddle-node bifurcation [type I neural oscillator (Rinzel and Ermentrout, 1989; Ermentrout, 1996)] (Fig. 2C, fixed point bifurcations). Tonic firing and slow bursting coexisted for $\left[\mathrm{K}^{+}\right]_{\mathrm{o}}$ between 5.45 and $6.35 \mathrm{~mm}$. Slow bursting was the only stable state for $\left[\mathrm{K}^{+}\right]_{\mathrm{o}}$ between 6.35 and $9.45 \mathrm{~mm}$. At $\left[\mathrm{K}^{+}\right]_{\mathrm{o}}=9.46$ $\mathrm{mM}$, a new stable state corresponding to a depolarized state $\left(V_{\mathrm{m}}=-26.3 \mathrm{mV}\right)$ appeared by means of a subcritical Hopf bifurcation (Fig. 2C). The depolarized state coexisted with the slow bursting regimen in a narrow bistable region before it became the only stable state at $\left[\mathrm{K}^{+}\right]_{\mathrm{o}}=10.05 \mathrm{~mm}$ (Fig. $2 \mathrm{~A}$, right).

To further characterize the transition between tonic firing and slow bursting, we computed a Poincare cross section by calculating the values of intracellular calcium concentration $\left[\mathrm{Ca}^{2+}\right]_{\mathrm{i}}$ each time the membrane potential crossed the threshold $V_{\mathrm{m}}=-20$ $\mathrm{mV}$; these values were plotted as a function of $\left[\mathrm{K}^{+}\right]_{\mathrm{o}}$ (Fig. $2 \mathrm{~B}$, Poincare cross section). In such a representation, periodic oscillations (corresponding to limit cycles) are represented as points defined by a threshold crossing of a trajectory. This approach allows the graphical representation of changes in the nature of an oscillatory (firing) behavior as a function of a parameter. For a given value of $\left[\mathrm{K}^{+}\right]_{\mathrm{o}}$, a tonic spiking regimen is represented on this Poincare plot by a single point because $\left[\mathrm{Ca}^{2+}\right]_{\mathrm{i}}$ assumes the same value at $V_{\mathrm{m}}=-20 \mathrm{mV}$ for every spike. During a burst, however, $\left[\mathrm{Ca}^{2+}\right]_{\mathrm{i}}$ increases after each spike of a given burst. Therefore, a burst appears as a group of points each representing a single spike. In other words, a set of parallel lines in the Poincare plot (Fig. $2 \mathrm{~B}$, Poincare cross section) illustrates a range of $\left[\mathrm{K}^{+}\right]_{\mathrm{o}}$ values for which bursting occurred. We gradually increased and decreased $\left[\mathrm{K}^{+}\right]_{\mathrm{o}}$ to reveal the complete tonic firing and slow bursting region, respectively. The bistability between tonic firing and slow bursting was associated with a hysteresis (Fig. $2 \mathrm{~B}$, compare top and bottom plots). For increasing $\left[\mathrm{K}^{+}\right]_{\mathrm{o}}$, the cell stayed in tonic firing until slow bursting with spike inactivation became the only stable state at $\left[\mathrm{K}^{+}\right]_{\mathrm{o}}=6.40 \mathrm{~mm}$. Decreasing $\left[\mathrm{K}^{+}\right]_{\mathrm{o}}$ caused the cell to stay in slow bursting mode until tonic firing was the only stable state at $\left[\mathrm{K}^{+}\right]_{\mathrm{o}}=5.75 \mathrm{~mm}$ (different from Fig. $2 \mathrm{~A}$
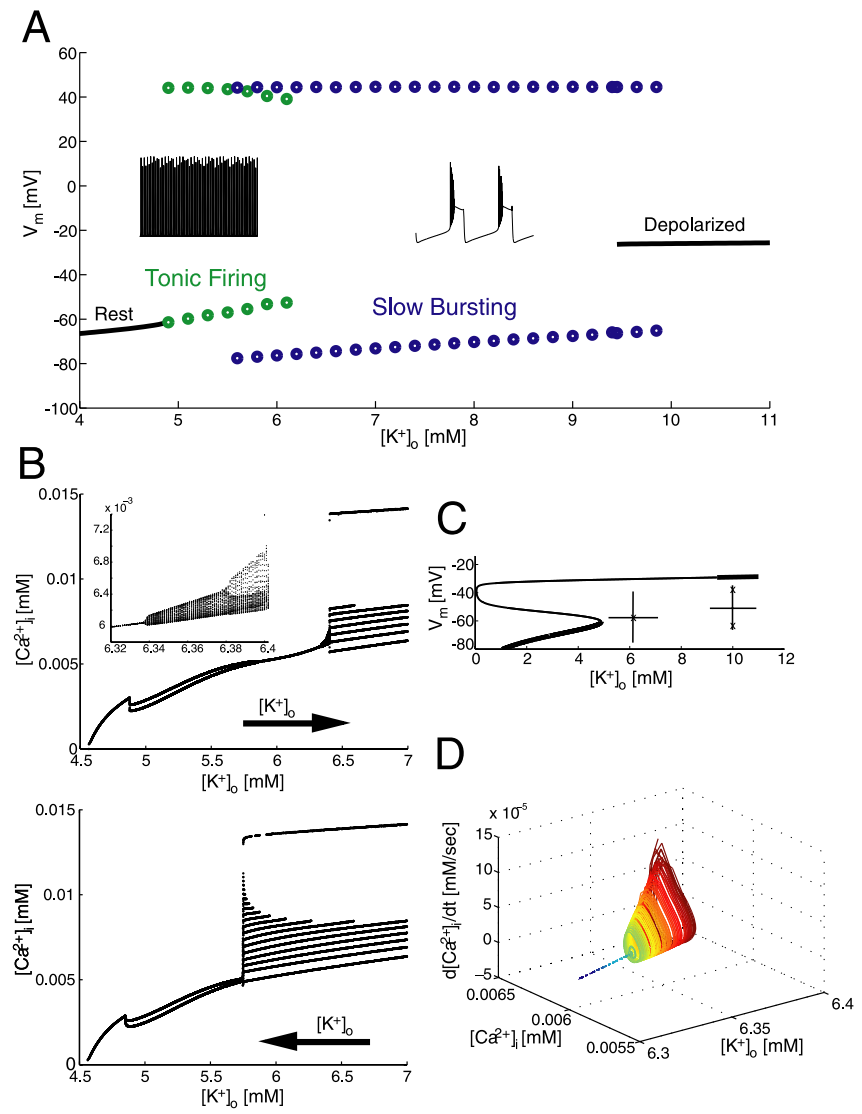

Figure 2. Bifurcation analysis of PY cell dynamics. $\boldsymbol{A}$, Maximum and minimum of membrane voltage as a function of $\left[\mathrm{K}^{+}\right]_{0}$. Solid lines, Stable fixed points. Circles, Stable limit cycles. Four stable states are found: rest, tonic firing, slow bursting, and a depolarized state, with bistability occurring between tonic firing and slow bursting and between slow bursting and the depolarized state $\left(G_{\mathrm{h}}=0.0 \mathrm{~m} \mathrm{~S} / \mathrm{cm}^{2}\right)$. B, Poincare cross section. Intracellular calcium concentration for $V_{\mathrm{m}}=-20 \mathrm{mV}$ as a function of slowly increasing (top) and decreasing (bottom) $\left[\mathrm{K}^{+}\right]_{0}$ is shown. Inset, Enlargement of transition from tonic firing to slow bursting $\left(G_{\mathrm{h}}=0.05 \mathrm{~m} \mathrm{~S} / \mathrm{cm}^{2}\right)$. C, Stable fixed points corresponding to rest and the depolarized state are connected via unstable fixed points. Transition from silent to tonic firing is a saddle-node bifurcation. Transition from slow bursting to depolarized is a Hopf bifurcation. Insets illustrate eigenvalues at the bifurcation point. $\boldsymbol{D}$, Three-dimensional representation of inset from $\boldsymbol{B}$ showing transition from tonic firing to frequency-modulated fast firing. Neimark-Sacker bifurcation of limit cycle leads to slow spike frequency modulation for $\left[\mathrm{K}^{+}\right]_{0}>6.33 \mathrm{~mm}$. Color scheme, From blue to red for low to high values of $\left[\mathrm{K}^{+}\right]_{0}$.

because now non-zero $\left.G_{\mathrm{h}}=0.05 \mathrm{mS} / \mathrm{cm}^{2}\right)$. For increasing $\left[\mathrm{K}^{+}\right]_{\mathrm{o}}$, the tonic firing region consisted of three subregions with single spikes, spike doublets, and single spikes, respectively (Fig. $2 B$, top). Time courses for spike doublets $\left(\left[\mathrm{K}^{+}\right]_{\mathrm{o}}=5.00 \mathrm{mM}\right)$ and single spikes $\left.\left[\mathrm{K}^{+}\right]_{\mathrm{o}}=6.00 \mathrm{~mm}\right)$ are shown in Figure $3, A$ and $B$, respectively. Note that the left region with single spikes existed only in the case of a nonzero h conductance $\left(G_{\mathrm{h}}=0.05 \mathrm{mS} / \mathrm{cm}^{2}\right)$. At $\left[\mathrm{K}^{+}\right]_{\mathrm{o}}=6.39 \mathrm{~mm}$, tonic firing started to exhibit slow modulation of the membrane voltage and the spiking frequency (Fig. $3 C, D$, spectrogram). Detailed bifurcation analysis revealed that at $\left[\mathrm{K}^{+}\right]_{\mathrm{o}}=6.39 \mathrm{mM}$, the limit cycle corresponding to the tonic spiking lost its stability by a supercritical Neimark-Sacker bifurcation (Kuznetsov, 2004), leading to a stable invariant torus in the phase space representation of the dynamical system (Fig. 2D). This type of behavior was not found for decreasing $\left[\mathrm{K}^{+}\right]_{\mathrm{o}}$ (Fig. $2 B$, bottom). Instead, two distinct bursting regimens, with and without spike inactivation, were found (Fig. $3 E, F$ ). For these bursts, transition from silent state to spiking (burst onset) occurred through a saddle-node bifurcation of the fixed point cor- 
A
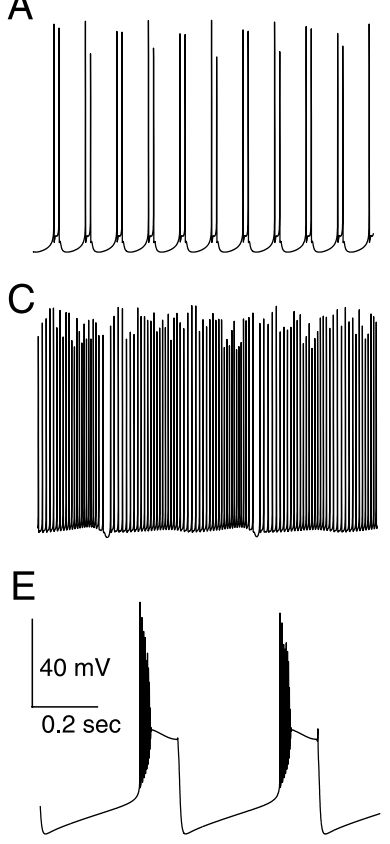

$\mathrm{F}$
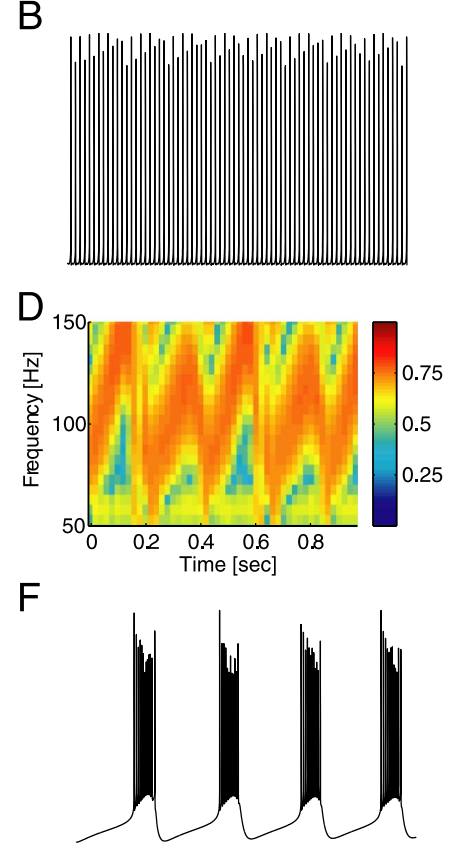

Figure 3. Time course of membrane voltage (1 s duration) for different values of $\left[\mathrm{K}^{+}\right]_{0} \cdot \boldsymbol{A}$, Spike doublets for $\left[\mathrm{K}^{+}\right]_{0}=5.00 \mathrm{~mm}$. $\boldsymbol{B}$, Fast tonic firing for $\left[\mathrm{K}^{+}\right]_{0}=6.00 \mathrm{~mm}$ (tonic firing branch, $\left[\mathrm{K}^{+}\right]_{0}$ increasing). C, Fast tonic firing modulated by slow oscillation corresponding to Neimark-Sacker bifurcation of limit cycle and consecutive torus bifurcation with period doubling for $\left[\mathrm{K}^{+}\right]_{0}=6.39 \mathrm{~mm}$ (tonic firing branch, $\left[\mathrm{K}^{+}\right]_{0}$ increasing). $\boldsymbol{D}$, Spectrogram of $\boldsymbol{C}$; normalized arbitrary units. E, Bursting with spike inactivation for $\left[\mathrm{K}^{+}\right]_{0}=6.00 \mathrm{~mm}$ (slow bursting branch, $\left[\mathrm{K}^{+}\right]_{0}$ decreasing). $\boldsymbol{F}$, Bursting without spike inactivation for $\left[\mathrm{K}^{+}\right]_{0}=5.75 \mathrm{~mm}$ (slow bursting branch, $\left[\mathrm{K}^{+}\right]_{0}$ decreasing).

responding to the silent (hyperpolarized) state. Return to the silent state (burst offset) occurred through a Hopf bifurcation of the fixed point corresponding to the depolarized (upper) state. Activation of $I_{\mathrm{K}(\mathrm{Ca})}$ (slow variable) controlled the transitions between silent and oscillatory states during bursts (data not shown).

The biophysical mechanism for the bistability with hysteresis between tonic firing and slow bursting was examined by (1) comparing the ionic currents in both regimens for $\left[\mathrm{K}^{+}\right]_{\mathrm{o}}=6.00 \mathrm{mM}$ (supplemental Fig. 2, available at www.jneurosci.org as supplemental material) and (2) systematically varying the intrinsic conductances involved in burst generation (supplemental Fig. 3, available at www.jneurosci.org as supplemental material). We found that the different levels of deinactivation of the highthreshold calcium current $I_{\mathrm{Ca}}$ explain the hysteresis between tonic firing and bursting. $I_{\mathrm{Ca}}$ reinforced bursting and therefore increased the range of $\left[\mathrm{K}^{+}\right]_{0}$ values for which the neuron stayed in bursting mode. In contrast, when the neuron was in tonic firing mode, insufficient $I_{\mathrm{Ca}}$ deinactivation between spikes prevented switching to the bursting mode unless $\left[\mathrm{K}^{+}\right]_{\mathrm{o}}$ was strongly elevated (supplemental Fig. 2, bottom panels, available at www. jneurosci.org as supplemental material). To confirm the role of $I_{\mathrm{Ca}}$ and to test the robustness of our model, we separately varied the three intrinsic conductances $G_{\mathrm{Ca}}, G_{\mathrm{NaP}}$, and $G_{\mathrm{KCa}}$ involved in initiating, sustaining, and terminating bursts, to study their impact on the bistability with hysteresis between tonic firing and bursting. Further, the effect of introducing a hyperpolarizationactivated depolarizing conductance $G_{\mathrm{h}}$ was examined. As anticipated, the width of the hysteresis between tonic firing and bursting varied with $G_{\mathrm{Ca}}$, whereas changes in the other conductances had minimal impact on the qualitative nature of the hysteresis (supplemental Fig. 3, available at www.jneurosci.org as supple-
A
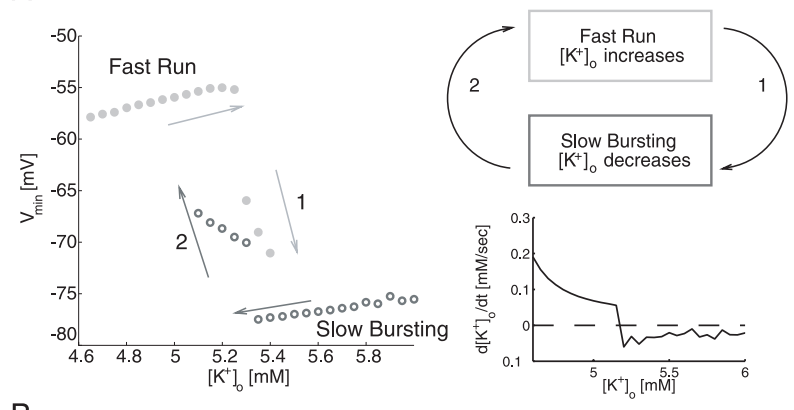

B
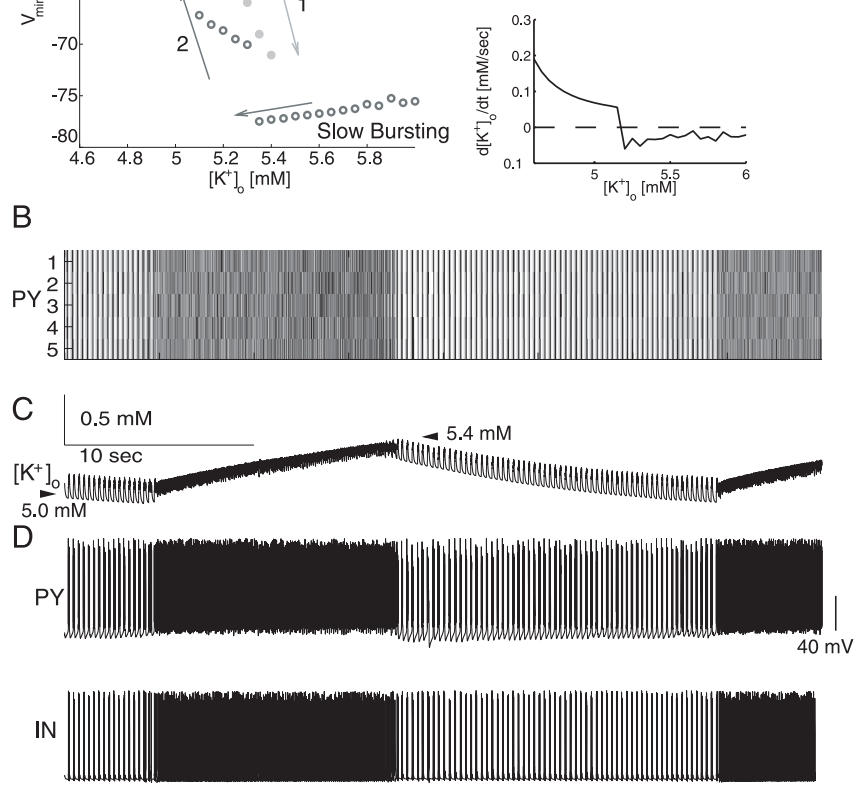

Figure 4. Globally connected network with five PY cells and one IN. A, Left, Bifurcation analysis (minimum of membrane voltage): hysteresis between fast run and slow bursting for $\left[\mathrm{K}^{+}\right]_{0}$ between 5.0 and $5.4 \mathrm{~mm}$. Circles denote stable limit cycle oscillations. Top right, Schematic of slow periodic network dynamics. Bottom right, Averaged $\left[K^{+}\right]_{0}$ change rate as a function of $\left[\mathrm{K}^{+}\right]_{0}$. $\boldsymbol{B}-\boldsymbol{D}$, Slow transitions after initial brief increase in $\left[\mathrm{K}^{+}\right]_{0} . \boldsymbol{B}$, Network activity of PY cells (40 s duration) shows alternating epochs of fast run and slow bursting. $C,\left[\mathrm{~K}^{+}\right]_{0}$ increased during fast run and decreased during slow bursting. The upper switching point for transition from fast run to slow bursting and the lower switching point for transition from slow bursting to fast run correspond to hysteresis endpoints in $\boldsymbol{A}$. $\boldsymbol{D}$, Membrane voltage time course of PY cell (top trace) and of IN (bottom trace).

mental material). These findings indicate the pivotal role of the high-threshold calcium conductance $G_{\mathrm{Ca}}$ in mediating bistability between the two oscillatory firing regimens.

\section{Slow transitions between oscillatory states in small network}

To determine whether the hysteresis between tonic firing and slow bursting was maintained in a network of neurons, we studied a network consisting of five PY cells with all-to-all excitatory coupling and one IN, which mediated global inhibition. When $\left[\mathrm{K}^{+}\right]_{\mathrm{o}}$ was held at various fixed values, four different states equivalent to those in the single cell model were found: silence, fast run, slow bursting, and a depolarized state (Fig. $4 A$, left, transition from fast run to slow bursting). Fast run (fast bursting with 2-4 spikes) corresponded to tonic firing found in the single cell model. Each of the three transitions between neighboring states was associated with a hysteresis, confirming that the hystereses found in the single cell model were indeed maintained in the small network.

When $\left[\mathrm{K}^{+}\right]_{\mathrm{o}}$ was released and continuously updated based on $\mathrm{K}^{+}$currents, $\mathrm{K}^{+}$pumps, and glial buffering (Eq. 5), a major difference between the single-cell model and the network model was found. For a single PY cell surrounded by an extracellular compartment, $\left[\mathrm{K}^{+}\right]_{\mathrm{o}}$ decreased steadily during both tonic spiking and bursting. Thus, the hysteresis between tonic firing and slow bursting had no effect on neural dynamics triggered by ele- 
vated $\left[\mathrm{K}^{+}\right]_{\mathrm{o}}$ because the cell never switched back from tonic firing to bursting. In the small network, however, the cells did not return to rest after the initial $\left[\mathrm{K}^{+}\right]_{\mathrm{o}}$ injection but instead displayed self-sustained oscillations with periodic alternations between fast run and slow bursting (Fig. $4 B$, activity of all five PY cells as a function of time for $40 \mathrm{~s}) \cdot\left[\mathrm{K}^{+}\right]_{\mathrm{o}}$ increased during fast run, which caused a transition of the network to the slow bursting regimen as predicted by the upper endpoint of the hysteresis found by bifurcation analysis (Fig. $4 A$, arrow 1, top right). If there were no hysteresis, this would lead to an immediate return to fast run because $\left[\mathrm{K}^{+}\right]_{\mathrm{o}}$ decreased during slow bursting. Because of the hysteresis, however, slow-bursting mode was maintained until the lower transition point for $\left[\mathrm{K}^{+}\right]_{\mathrm{o}}$ back to fast run was reached, where the cycle restarted (Fig. $4 A$, arrow 2, top right). By averaging over many periods during fast run and a single period during slow bursting, we determined the time derivative of extracellular potassium concentration as a function of $\left[\mathrm{K}^{+}\right]_{\mathrm{o}}$ if it were free to change. This further illustrates the fact that $\left[\mathrm{K}^{+}\right]_{\mathrm{o}}$ increases during fast run and decreases during slow bursting (Fig. $4 A$, bottom right, dashed line represents $\mathrm{d}\left[\mathrm{K}^{+}\right]_{\mathrm{o}} / \mathrm{dt}=0$ "nullcline"). The dependence of the lower and upper transition points on whether $\left[\mathrm{K}^{+}\right]_{\mathrm{o}}$ was increasing or decreasing matched the prediction from bifurcation analysis (Fig. $4 A$, end points of hysteresis). Thus, synaptic interaction stabilized the network in the hysteresis region between fast run and slow bursting $\left(\left[\mathrm{K}^{+}\right]_{\mathrm{o}}\right.$ between 5.0 and $5.4 \mathrm{~mm}$ ). Synchrony is not required for this mechanism to work as long as the time derivatives of potassium follow this general rule. Rather, overall excitation mediated by network interaction needs to provide sufficient excitatory drive for firing frequencies, which enable potassium to increase during tonic firing (fast run) without causing a switch to the bursting regimen. Note that a single PY cell with a self-excitatory synapse did not exhibit these transitions (data not shown); it displayed either bursting (for strong coupling) or tonic firing (for weak coupling). Because the inhibitory interneuron was active during epochs of fast run, the spike structure of the fast run was different between the single cell and small network models. PY neurons from the network displayed fast oscillations with groups of spikes separated by short hyperpolarizing events mediated by IPSPs. When excitatory input to the inhibitory interneurons was reduced such that they became silent during fast run, PY neurons displayed tonic spiking activity similar to the single-cell model (supplemental Fig. 4, available at www.jneurosci.org as supplemental material).

Single-cell model analysis revealed that high-threshold calcium current $I_{\mathrm{Ca}}$ inactivation was critical for determining the oscillatory mode (tonic spiking or bursting). In an additional set of simulations, we extended this finding to the network model by perturbing inactivation variable $h$ of $I_{\mathrm{Ca}}$ for all neurons in the network to induce switching between the two oscillatory states (supplemental Fig. 5, available at www.jneurosci.org as supplemental material). The network switched from fast run to slow bursting when enforcing a value of $h=0.53$ (mean value between bursts) for $0.25 \mathrm{~s}$. Similarly, imposing a value of $h=0.36$ (mean value during fast run) for $1 \mathrm{~s}$ during slow bursting caused the network to switch to fast run.

\section{Role of synaptic conductances}

Network interaction was critical for the occurrence of alternating epochs of fast run and slow bursting. Therefore, we systematically varied the synaptic strength to uncover its specific effect on the network dynamics. Increasing excitation (PY-PY coupling) without changing inhibition $\left(\mathrm{IN}-\mathrm{PY}=1.1\right.$ ) widened the $\left[\mathrm{K}^{+}\right]_{\mathrm{o}}$
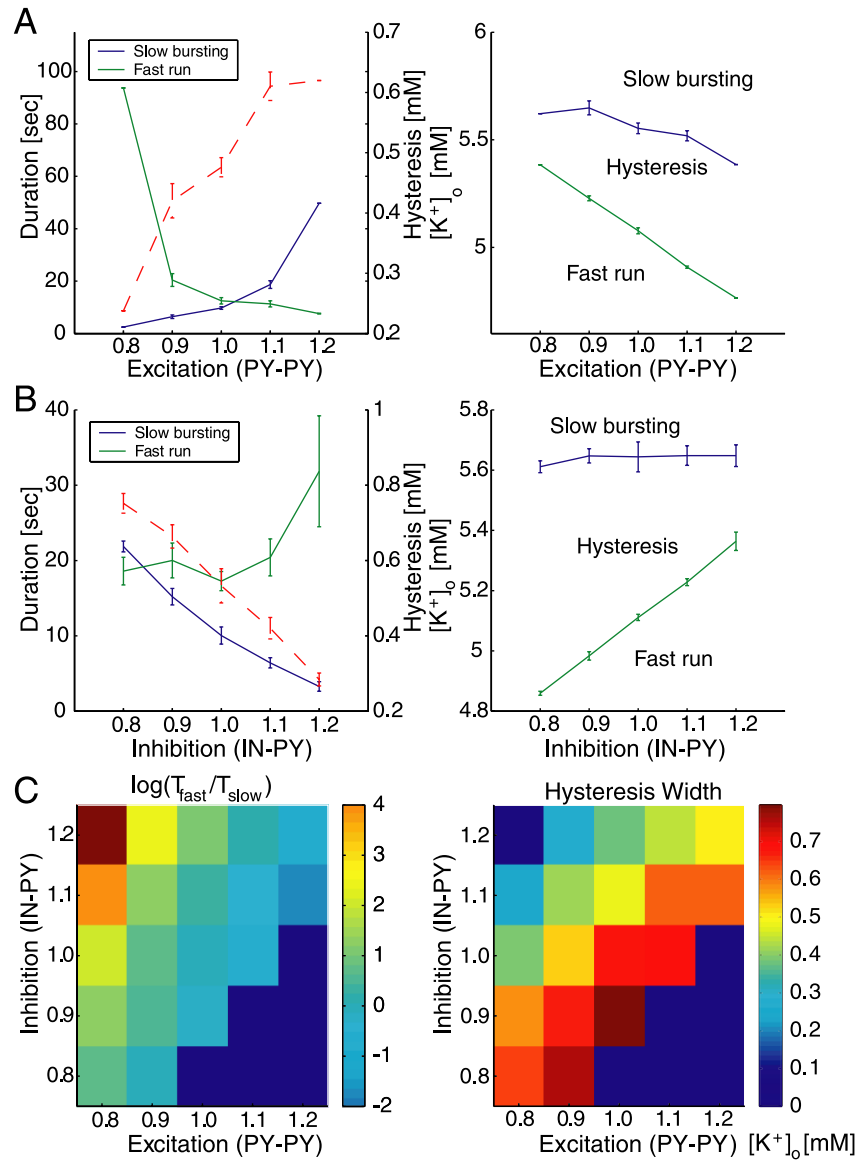

Figure 5. Quantification of periodic slow transitions between slow bursting and fast run as a function of excitatory and inhibitory coupling. Balanced excitation and inhibition causes alternating epochs of slow bursting and fast run. Left, Duration of epochs of slow bursting and fast run (blue and green solid lines, respectively), width of hysteresis (dashed red line), and upper and lower endpoints of hysteresis (right) for changing excitatory coupling ( $\boldsymbol{A}$ ) (PY-PY) and inhibitory coupling (IN-PY) (B). Values determined from simulation of $400 \mathrm{~s}$ of activity are shown. Error bars indicate SEM. C, Overview plot showing logarithmic ratio of duration of fast run and slow bursting (left) and width of hysteresis (right) as a function of synaptic excitation and inhibition. The top left corner corresponds to the regimen with exclusive fast run, whereas the bottom right corner denotes the regimen with exclusive slow bursting.

hysteresis (from 0.24 to $0.62 \mathrm{~mm}$ for PY-PY $=0.8$ and 1.2 , respectively) (Fig. $5 \mathrm{~A}$, left, dashed line) and prolonged the episodes of slow bursting at the expense of fast run (solid lines). The increase in hysteresis width was mainly caused by a lower value of $\left[\mathrm{K}^{+}\right]_{\mathrm{o}}$ for which the network switched from slow bursting to fast run (from 5.38 to $4.77 \mathrm{~mm}$ for PY-PY $=0.8$ and 1.2 , respectively) (Fig. 5A, right). In contrast, increasing inhibition (IN-PY coupling) without changing excitation (PY-PY $=0.9$ ) shortened epochs of slow bursting and prolonged epochs of fast run, respectively (Fig. $5 B$, left, solid lines). The $\left[\mathrm{K}^{+}\right]_{\mathrm{o}}$ hysteresis was narrowed (from 0.75 to $0.28 \mathrm{~mm}$ for IN-PY $=0.8$ and 1.2, respectively) (Fig. $5 B$, left, dashed line), mostly by an increase in the range of $\left[\mathrm{K}^{+}\right]_{\mathrm{o}}$ for which fast run was the only stable state (from 4.86 to $5.36 \mathrm{~mm}$ for $\mathrm{IN}-\mathrm{PY}=0.8$ and 1.2 , respectively). Thus, during fast run, $\left[\mathrm{K}^{+}\right]_{\mathrm{o}}$ increased more slowly because of the reduced firing frequency. Additionally, increased inhibition forced the network back to fast run for higher $\left[\mathrm{K}^{+}\right]_{\mathrm{o}}$ (Fig. $5 B$, right). Examples of nonalternating regimens resulted from major changes in the balance between excitation and inhibition (Fig. $5 C$, right, areas in dark blue). For strong excitation and weak inhibition, the network returned to the silent state after a single 
A

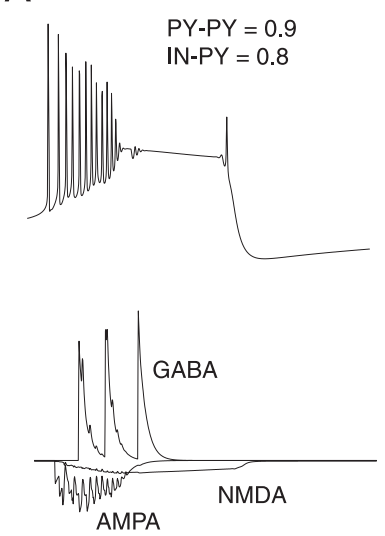

B
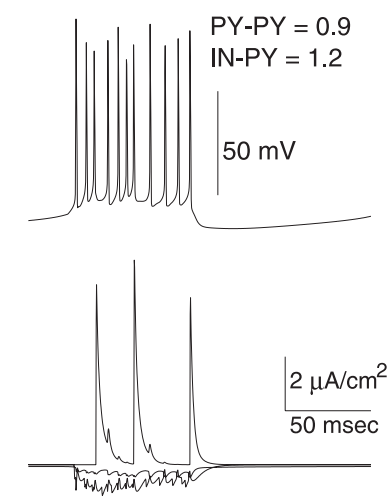

C
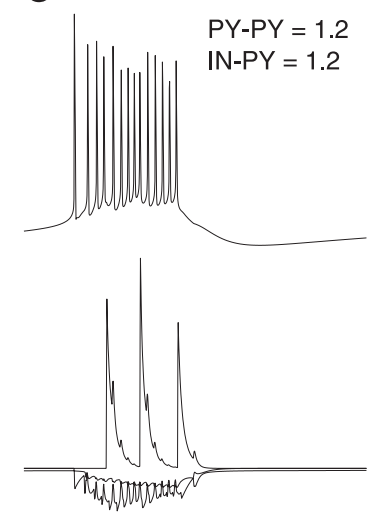

Figure 6. Time course of burst and underlying synaptic currents for three different synaptic configurations. First row, Membrane voltage time course. Second row, Total synaptic current on PY cell. $\boldsymbol{A}$, Weak excitation and weak inhibition (scaling factors: $P Y-P Y=0.9$ and IN-PY $=0.8$ ). $\boldsymbol{B}$, Weak excitation and strong inhibition (scaling factors: PY-PY $=0.9$ and IN-PY $=1.2) . C$, Strong excitation and strong inhibition (scaling factors: $P Y-P Y=1.2$ and $I N-P Y=1.2$ ).

A

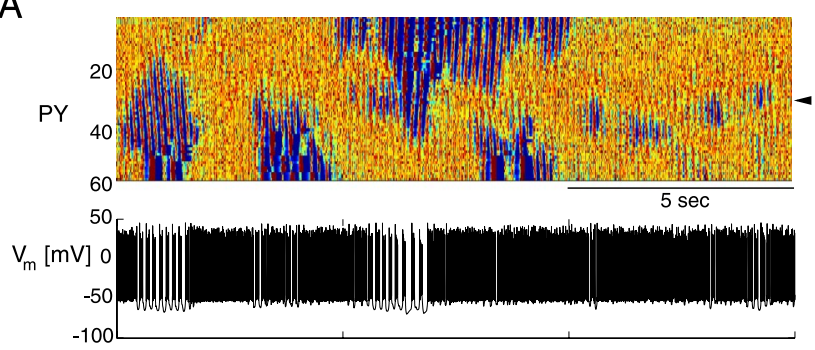

B
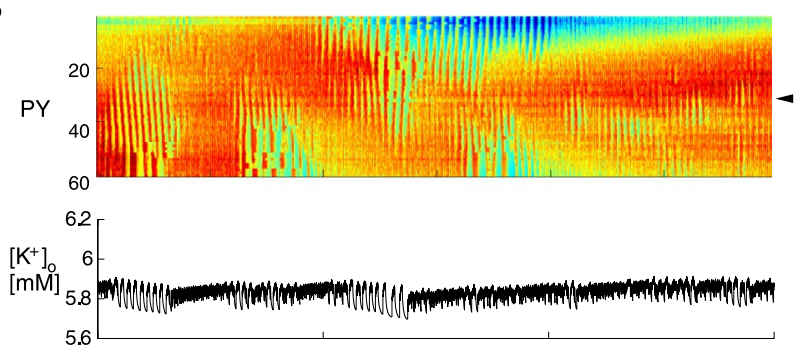

C
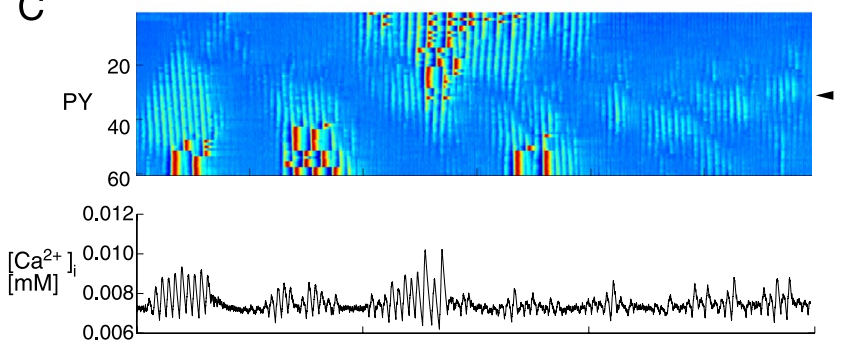

Figure 7. Large network (60 PY cells and $15 \mathrm{INs}$ ) with local synaptic connectivity. $\boldsymbol{A}, \mathrm{PY}$ cell activity as a function of time (top). The time course of $V_{m}$ for PY 30 is shown (bottom, arrow in top). Cells switched between bursting and fast run as in the case of the small network. Because of the local synaptic connectivity, the activity pattern exhibited complex spatial structure. $\boldsymbol{B}$, $\left[\mathrm{K}^{+}\right]_{0}$ in extracellular compartments surrounding PY cells as a function of time (top). The time course of $\left[\mathrm{K}^{+}\right]_{0}$ for PY 30 is shown (bottom, arrow in top). C, Intracellular calcium $\left[\mathrm{Ca}^{2+}\right]_{\mathrm{i}}$ in PY cells as a function of time. The time course of $\left[\mathrm{Ca}^{2+}\right]_{\mathrm{i}}$ for PY 30 is shown (bottom, arrow in top). Color scheme in $\boldsymbol{B}$ and $\boldsymbol{C}$, From blue to red for low to high values of ionic concentration.

epoch of bursting. Conversely, strong inhibition and weak excitation led to sustained fast run (supplemental Fig. 6, time courses, available at www.jneurosci.org as supplemental material). Combinatorial variation of both excitatory (PY-PY) and inhibitory
(IN-PY) synaptic coupling strength showed that the existence of the transitions between fast run and slow bursting is robust to changes in synaptic connectivity as long as the balance between excitatory and inhibitory coupling was maintained. Both the logarithmic ratio of the duration of fast run and slow bursting episodes and the width of the hysteresis were only slightly affected by changes in synaptic connectivity strength as long as excitation and inhibition was scaled accordingly (Fig. $5 C$, diagonal structure).

Bursts differed in their characteristics depending on the balance between excitation and inhibition (Fig. 6). In the case of reduced excitation $(\mathrm{PY}-\mathrm{PY}=0.9)$ and inhibition ( $\mathrm{IN}-\mathrm{PY}=0.8$ ), bursts exhibited a gradual decline in spike amplitude, spike inactivation, and a pronounced afterhyperpolarization (Fig. 6A, first row). Excitatory AMPAergic input to PY cells built up during spiking at the onset of the burst. NMDA current was active until burst termination (Fig. 6A, second row). For increased inhibition (IN$\mathrm{PY}=1.2$ ) (Fig. $6 B$ ), bursts showed decreased spiking frequency and lacked both spike inactivation and after-hyperpolarization. Excitatory synaptic currents mediated by AMPA and NMDA receptors were of the same order of magnitude and similar duration. Balancing increased inhibition $(\mathrm{IN}-\mathrm{PY}=1.2)$ by strengthening excitation (PY-PY = 1.2) increased both firing frequency within the burst and the total number of spikes per burst (Fig. $6 C$ ). Fast run spiking structure was less sensitive to moderate changes in the balance between excitation and inhibition, as long as the inhibitory interneuron remained active during periods of fast runs (supplemental Fig. 4, available at www.jneurosci.org as supplemental material).

\section{Slow transitions of oscillatory states in large network}

In a larger network consisting of $60 \mathrm{PY}$ cells and $15 \mathrm{INs}$ with local synaptic connectivity, each PY neuron switched between fast run and slow bursting at a similar time scale, as in the case of the small, compact network (Fig. 7A, top: network activity as a function of time, bottom: single membrane voltage trace). In contrast to the small network, however, state transitions did not occur synchronously across the network. Rather, a given PY cell that reached the $\left[\mathrm{K}^{+}\right]_{\mathrm{o}}$ required for a state transition first switched its oscillatory firing mode and induced an according transition in the neighboring PY cells by synaptic coupling. Epochs of slow bursting or fast run therefore spread in neighboring cells. In other words, state transitions were induced according to the hysteresis in the leading neurons, which were the cells with the highest $\left[\mathrm{K}^{+}\right]_{\mathrm{o}}$ (Fig. $7 B$, top). Transitions in the neighboring cells were then promoted by the synaptic coupling. This resulted in a multitude of switching points for each neuron (Fig. $7 B$, bottom). The behavior of the neurons initiating network transitions was governed according to the bistability described before. Intracellular calcium $\left[\mathrm{Ca}^{2+}\right]_{\mathrm{i}}$ was highly elevated during paroxysmal activity $(>0.004 \mathrm{~mm})$, in comparison to the equilibrium value at the resting potential $(0.0001 \mathrm{mM}) .\left[\mathrm{Ca}^{2+}\right]_{\mathrm{i}}$ remained more or less constant during epochs of fast run and oscillated during bursting (Fig. $7 C$, top) because $I_{\mathrm{Ca}}$ was the major contributor to the burst depolarization. In any given PY neuron, peak value of $\left[\mathrm{Ca}^{2+}\right]_{\mathrm{i}}$ almost doubled during each burst (Fig. $7 C$, bottom). Including 
lateral $\mathrm{K}^{+}$diffusion did not change the global structure of alternating epochs of fast run and slow bursting (data not shown).

\section{Slow transitions of oscillatory states in vivo}

We recorded paroxysmal activity with similar patterns of sustained transitions between fast run and slow bursting from association areas 5 and 7 in anesthetized cats (Fig. 8). Cats under ketamine-xylazine anesthesia reveal a sleep-like slow oscillatory pattern with frequency $0.8-0.9 \mathrm{~Hz}$ (Steriade and Contreras, 1998). In 31 cats $(n=45)$, we found spontaneous paroxysmal discharges consisting of spike-wave (polyspike-wave) complexes (slow bursting, 1.5-3 Hz) and epochs of fast run (fast spiking, $8-15 \mathrm{~Hz}$ ). In average, 2.4 (SD 1.4) episodes of fast run occurred during a seizure. Episodes of slow bursting and fast run lasted $37.2 \mathrm{~s}$ (SD 22.2) and $4.9 \mathrm{~s}$ (SD 5.7 ), respectively. The mechanism of these slow transitions is unknown. Our modeling work reproduces the qualitative features of these transitions between slow bursting and fast run and therefore suggests activity-dependent modulation of excitability (e.g., extracellular potassium dynamics) as a candidate mechanism.
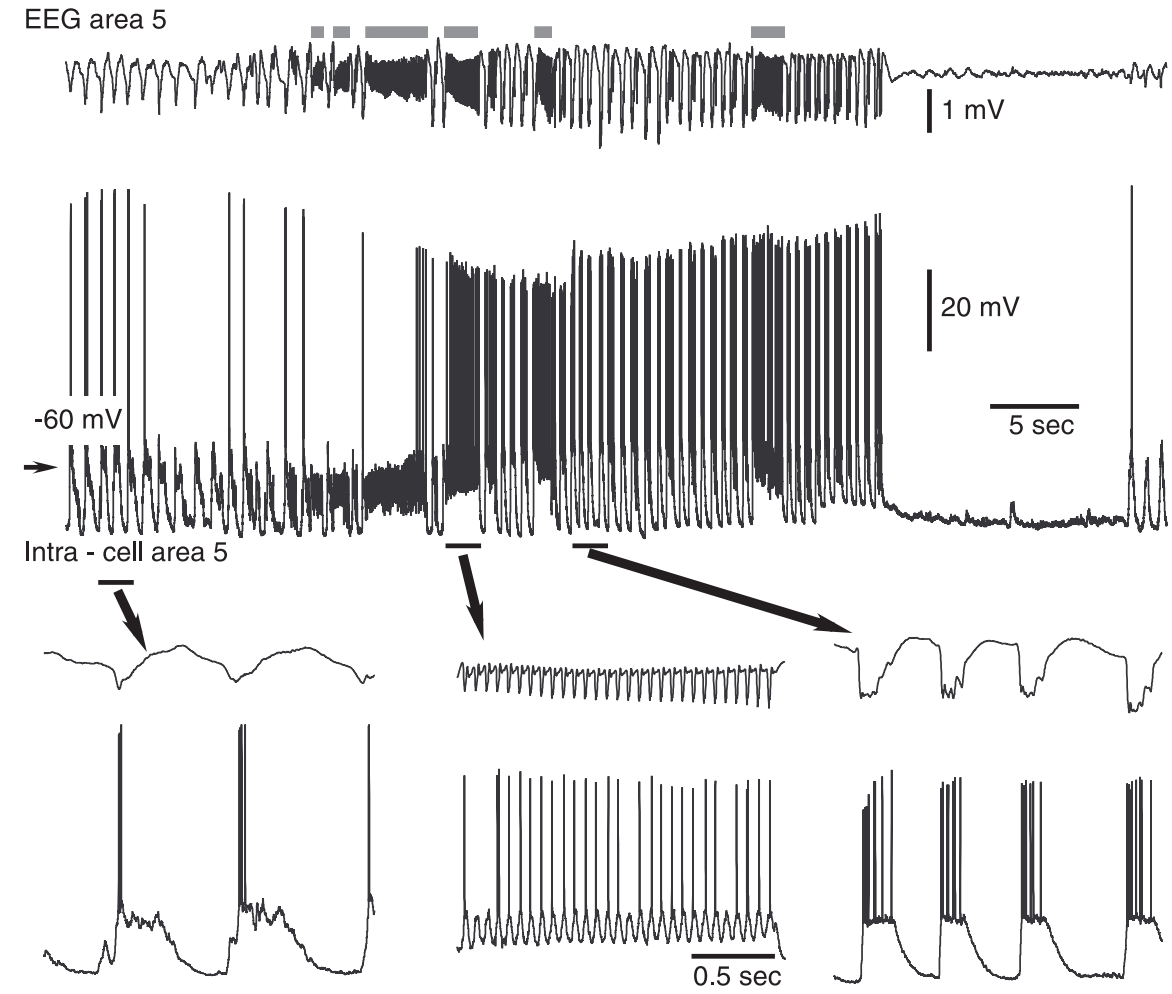

Figure 8. Sample trace of electrographic seizure composed of alternating epochs of spike-wave complexes (slow bursting) and fast run. Top, Depth EEG and intracellular activity during normal slow oscillation and its transformation to paroxysmal activity composed of fast runs and spike-wave complexes. Thick gray lines indicate periods of fast runs. The other periods of the seizure are spike-wave complexes. Three expanded fragments indicated by horizontal bars and arrows show (from left to right) a period of slow oscillation, a paroxysmal fast run, and a period of spike-wave discharges (slow bursting).

\section{Discussion}

Extracellular potassium concentration, $\left[\mathrm{K}^{+}\right]_{\mathrm{o}}$, reflects past firing activity. In turn, elevated $\left[\mathrm{K}^{+}\right]_{\mathrm{o}}$ increases the intrinsic excitability of neurons. Yet, very little is known about the dynamics of such activity-dependent modulation of intrinsic excitability. $\mathrm{K}^{+}$dependent regulation of neuronal activity essentially provides a positive feedback mechanism that can lead to tonic depolarization and to instability exhibited through high-frequency sustained firing. Here we found, however, that dynamic interplay of fast processes (mediated by intrinsic and synaptic conductances) and $\left[\mathrm{K}^{+}\right]_{\mathrm{o}}$ dynamics can mediate very slow transitions between two different oscillatory states in conditions of balanced excitation and inhibition for elevated $\left[\mathrm{K}^{+}\right]_{\mathrm{o}}$. Thus, the inherently positive feedback mechanism of extracellular potassium dynamics stabilizes cortical network oscillations and causes sustained neural firing structured into alternating periods of fast run and slow bursting.

\section{Bistability and hysteresis}

In our neocortical network models, we found a bistability with hysteresis between tonic firing and slow bursting under conditions of balanced excitation and inhibition. Thus, the hysteresis causes a sustained pattern of alternating episodes of fast and slow oscillations in the absence of external input. Network connectivity was critical to maintain oscillations. Although the hysteresis between several oscillatory states was found already in a single cell model, those states appeared only transiently after initial stimulation. Balanced excitatory and inhibitory connections between pyramidal cells and interneurons were essential to stabilize the network in the regimen of alternating modes. After an initial increase in $\left[\mathrm{K}^{+}\right]_{\mathrm{o}}$, a small globally connected PY-IN network exhibits periodic transitions between fast run and slow bursting every few seconds. During fast run, the spiking frequency is sufficiently high for extracellular $\mathrm{K}^{+}$to accumulate. When $\left[\mathrm{K}^{+}\right]_{\mathrm{o}}$ reaches the upper endpoint of the hysteresis, the network switches back to slow bursting, during which $\left[\mathrm{K}^{+}\right]_{\mathrm{o}}$ decreases until it reaches the lower endpoint of the hysteresis for transition to fast run. We showed that a similar mechanism also occurs in larger networks with more realistic synaptic connectivity where oscillatory regimens are initiated and driven by $\left[\mathrm{K}^{+}\right]_{\mathrm{o}}$ dynamics.

Various types of potassium-mediated bistabilities have been described in both experimental and theoretical studies. Elevated $\left[\mathrm{K}^{+}\right]_{\mathrm{o}}$ led to a bistability between tonic firing and quiescence in a model of a hippocampal pyramidal cell (Hahn and Durand, 2001). Exposing cardiac Purkinje fibers to changing $\mathrm{K}^{+}$concentration revealed two stable levels of resting potentials; switching between these two stable states was associated with a hysteresis (Gadsby and Cranefield, 1977). A simplified model of cerebellar Purkinje cells comprised of high-threshold calcium and delayedrectifier potassium channels reproduced an experimentally observed bistability between resting potential and a depolarized state (Yuen et al., 1995). Myocardial cells exhibited two stable levels of diastolic potential when exposed to $4 \mathrm{mM} \mathrm{K}^{+}$in vitro (McCullough et al., 1990).

In contrast to these studies, we investigated here a novel bistability between two different oscillatory firing regimens. In our model, $\left[\mathrm{K}^{+}\right]_{\mathrm{o}}$ dynamics not only created bistability but also forced periodic transitions between two metastable oscillatory states. The rate of $\left[\mathrm{K}^{+}\right]_{\mathrm{o}}$ change depends on the balance between neuronal $\mathrm{K}^{+}$currents, $\mathrm{K}^{+}$pumps, and glial buffering and, therefore, can be arbitrarily slow. Because of this, the time scale of slow 
transitions between oscillatory states in the model was not explicitly restricted by the time constants of any intrinsic or synaptic conductances. The relative duration of the different oscillatory modes depended on the width of hysteresis that was controlled by the combination of intrinsic and synaptic currents. Thus, mechanisms proposed in this work can potentially explain a wide range of oscillatory phenomena different by the time scale of oscillations and duration of alternating modes.

Other mechanisms may create multistability in synaptically coupled networks. Synaptic depression mediated bistability between two modes of oscillations in networks with recurrent inhibitory connectivity (Manor and Nadim, 2001). Bistability between silence and firing mediated by nonlinear firing characteristics of neurons and by feedback between the two neurons was found in small biological circuits in vitro (Kleinfeld et al., 1990). Although all of these mechanisms may potentially explain periodic transitions between different network states, an explicit assumption about the time constant of plasticity that should match the time constant of the slow transitions between modes is required. Our model is free from this limitation. As we showed here, interaction in a population of neurons (or neuronal circuits) mediated by extracellular ionic concentrations may lead to complex oscillatory regimens with continuous and arbitrarily slow transitions between individual stable modes.

\section{Balanced excitation and inhibition}

In our model, extracellular potassium dynamics caused sustained neural oscillations with alternating epochs of slow bursting and fast run, provided synaptic excitation and inhibition was balanced. Substantial change of the excitatory PY-PY or inhibitory IN-PY coupling away from the balanced state created regimens with exclusive fast tonic oscillations or slow bursting. The concept of balanced synaptic excitation and inhibition plays a central role in many neurobiological processes. Experimental in vivo, in vitro, and modeling studies of transitions between cortical active and silent states showed that periods of high activity are accompanied by a decrease in input resistance mediated by a simultaneous increase in both excitation and inhibition (Steriade et al., 2001; Bazhenov et al., 2002; Compte et al., 2003). Self-sustained activity mediated by balanced synaptic inputs might underlie short-term memory (Durstewitz et al., 2000) and the modulation of neuronal excitability with attention (Mehta et al., 2000). We find it notable that potentially similar conditions for the balance between excitation and inhibition can allow different forms of self-sustained activity and state-dependent transitions between different activity regimens.

Our model sheds a new light on the interaction between excitatory and inhibitory synaptic coupling during cortical oscillations. Traditionally, the role of inhibitory interneurons is to maintain reasonable firing frequency levels, and a shift in the balance between excitation and inhibition toward excitation is often associated with epileptic states (Dichter and Ayala, 1987; Tasker and Dudek, 1991; Galarreta and Hestrin, 1998; Nelson and Turrigiano, 1998). A number of studies conclude, however, that synaptic inhibition remains functional in many forms of paroxysmal activities (Higashima, 1988; Davenport et al., 1990; Traub et al., 1996; Esclapez et al., 1997; Prince et al., 1997; Cohen et al., 2002; Timofeev et al., 2002; Engel et al., 2003; Topolnik et al., 2003). In agreement with these findings, the role of inhibition is rather subtle in our model. If the balance of excitation and inhibition is shifted toward excitation, the PY cells were sufficiently active to stay in the bursting mode and fast run never occurred. Because $\left[\mathrm{K}^{+}\right]_{\mathrm{o}}$ decreased progressively during burst- ing, the network switched to the silent state. Thus, contrary to what was expected, decrease of inhibition in the model terminated oscillations because a single epoch of slow bursting was followed by silence (supplemental Fig. 6, available at www. jneurosci.org as supplemental material).

Synaptic plasticity can change the balance between excitation and inhibition and therefore move the network away from the region of sustained oscillations. These dynamic changes in synaptic weights could be especially prominent during high frequency synchronized paroxysmal oscillations. Therefore, the mechanism described in our model may potentially explain termination of the paroxysmal activity after seizures.

\section{Conclusion}

We describe a novel biophysical mechanism for slow periodic transitions between different oscillatory states of cortical networks. A positive feedback mechanism modulating intrinsic excitability caused metastable slow state transitions rather than unstable "run-away" dynamics as intuition might suggest. Such slow transitions between different oscillatory regimens have been observed in a number of in vivo recordings from different cortical structures. We expect the dynamics observed in our modeling work to be potentially valid for various brain states characterized by a (transient) increase in cellular excitability. Neocortical paroxysmal activity mediated by elevated extracellular $\mathrm{K}^{+}$concentration represents one "extreme" example of such a change in excitability. Other potential mechanisms include upregulation of some intrinsic depolarizing currents, increase of input resistance, or decrease in extracellular $\mathrm{Ca}^{2+}$ concentration. Specifically, our model predicts that (1) dynamic interaction of fast processes (such as intrinsic and synaptic conductances) in the system with a positive feedback mechanism controlling excitability (extracellular potassium dynamics) can introduce dynamics on a much slower time scale, (2) the slow patterning of sustained neuronal firing behavior into alternating epochs of tonic firing and bursting can be mediated by extracellular potassium dynamics, (3) balanced synaptic excitation and inhibition is required for maintaining the slow transition dynamics, and (4) the high-threshold calcium conductance plays an important role in creating sustained neural oscillations.

\section{References}

Amzica F, Massimini M, Manfridi (2002) A spatial buffering during slow and paroxysmal sleep oscillations in cortical networks of glial cells in vivo. J Neurosci 22:1042-1053.

Bazhenov M, Timofeev I, Steriade M, Sejnowski TJ (2002) Model of thalamocortical slow-wave sleep oscillations and transitions to activated states. J Neurosci 22:8691-8704.

Bazhenov M, Timofeev I, Steriade M, Sejnowski TJ (2004) Potassium model for slow $(2-3 \mathrm{~Hz})$ in vivo neocortical paroxysmal oscillations. J Neurophysiol 92:1116-1132.

Buzsaki G, Draguhn A (2004) Neuronal oscillations in cortical networks. Science 304:1926-1929.

Cohen I, Navarro V, Clemenceau S, Baulac M, Miles R (2002) On the origin of interictal activity in human temporal lobe epilepsy in vitro. Science 298:1418-1421.

Compte A, Sanchez-Vives MV, McCormick DA, Wang XJ (2003) Cellular and network mechanisms of slow oscillatory activity $(<1 \mathrm{~Hz})$ and wave propagations in a cortical network model. J Neurophysiol 89:2707-2725.

Connors BW, Gutnick MJ (1990) Intrinsic firing patterns of diverse neocortical neurons. Trends Neurosci 13:99-104.

Davenport CJ, Brown WJ, Babb TL (1990) Sprouting of GABAergic and mossy fiber axons in dentate gyrus following intrahippocampal kainate in the rat. Exp Neurol 109:180-190.

Destexhe A, Mainen ZF, Sejnowski TJ (1994) Synthesis of models for excitable membranes, synaptic transmission and neuromodulation using a common kinetic formalism. J Comput Neurosci 1:195-230. 
Dhooge A, Govaerts W, Kuznetsov YA (2003) MATCONT: A MATLAB package for numerical bifurcation analysis of ODEs. ACM Trans Math Softw 29:141-164.

Dichter MA, Ayala GF (1987) Cellular mechanisms of epilepsy: a status report. Science 237:157-164.

Durstewitz D, Seamans JK, Sejnowski TJ (2000) Neurocomputational models of working memory. Nat Neurosci 3 [Suppl]:1184-1191.

Engel Jr J, Wilson C, Bragin A (2003) Advances in understanding the process of epileptogenesis based on patient material: what can the patient tell us? Epilepsia 44 [Suppl 12]:60-71.

Ermentrout B (1996) Type I membranes, phase resetting curves, and synchrony. Neural Comput 8:979-1001.

Esclapez M, Hirsch JC, Khazipov R, Ben-Ari Y, Bernard C (1997) Operative GABAergic inhibition in hippocampal CA1 pyramidal neurons in experimental epilepsy. Proc Natl Acad Sci USA 94:12151-12156.

Gadsby DC, Cranefield PF (1977) Two levels of resting potential in cardiac Purkinje fibers. J Gen Physiol 70:725-746.

Galarreta M, Hestrin S (1998) Frequency-dependent synaptic depression and the balance of excitation and inhibition in the neocortex. Nat Neurosci 1:587-594.

Gil Z, Connors BW, Amitai Y (1997) Differential regulation of neocortical synapses by neuromodulators and activity. Neuron 19:679-686.

Hahn PJ, Durand DM (2001) Bistability dynamics in simulations of neural activity in high-extracellular-potassium conditions. J Comput Neurosci 11:5-18.

Heinemann U, Lux HD, Gutnick MJ (1977) Extracellular free calcium and potassium during paroxsmal activity in the cerebral cortex of the cat. Exp Brain Res 27:237-243.

Higashima M (1988) Inhibitory processes in development of seizure activity in hippocampal slices. Exp Brain Res 72:37-44.

Jahnsen H, Llinas R (1984a) Voltage-dependent burst-to-tonic switching of thalamic cell activity: an in vitro study. Arch Ital Biol 122:73-82.

Jahnsen H, Llinas R (1984b) Electrophysiological properties of guinea-pig thalamic neurones: an in vitro study. J Physiol (Lond) 349:205-226.

Jones CKRT (1995) Geometric singular perturbation theory. In: Dynamical systems: lectures given at the 2 nd session of the Centro Internazional Matemactico Estivo (C.I.M.E.) held in Montecatini Terme, Italy, June 13-22, 1994 (Johnson R, ed). New York, Springer.

Kleinfeld D, Raccuia-Behling F, Chiel HJ (1990) Circuits constructed from identified Aplysia neurons exhibit multiple patterns of persistent activity. Biophys J 57:697-715.

Kofuji P, Newman EA (2004) Potassium buffering in the central nervous system. Neuroscience 129:1045-1056.

Kuffler SW, Nicholls JG, Orkand RK (1966) Physiological properties of glial cells in the central nervous system of amphibia. J Neurophysiol 29:768-787.

Kuznetsov YA (2004) Elements of applied bifurcation theory, Ed 3. New York: Springer.

Lechner HA, Baxter DA, Clark JW, Byrne JH (1996) Bistability and its regulation by serotonin in the endogenously bursting neuron R15 in Aplysia. J Neurophysiol 75:957-962.

Mainen ZF, Sejnowski TJ (1996) Influence of dendritic structure on firing pattern in model neocortical neurons. Nature 382:363-366.

Manor Y, Nadim F (2001) Synaptic depression mediates bistability in neuronal networks with recurrent inhibitory connectivity. J Neurosci 21:9460-9470.

Markram H, Pikus D, Gupta A, Tsodyks M (1998) Potential for multiple mechanisms, phenomena and algorithms for synaptic plasticity at single synapses. Neuropharmacology 37:489-500.

McCormick DA (1992) Neurotransmitter actions in the thalamus and cerebral cortex and their role in neuromodulation of thalamocortical activity. Prog Neurobiol 39:337-388.

McCormick DA, Connors BW, Lighthall JW, Prince DA (1985) Comparative electrophysiology of pyramidal and sparsely spiny stellate neurons of the neocortex. J Neurophysiol 54:782-806.

McCullough JR, Chua WT, Rasmussen HH, Ten Eick RE, Singer DH (1990) Two stable levels of diastolic potential at physiological $\mathrm{K}+$ concentrations in human ventricular myocardial cells. Circ Res 66:191-201.

Mehta AD, Ulbert I, Schroeder CE (2000) Intermodal selective attention in monkeys. I. Distribution and timing of effects across visual areas. Cereb Cortex 10:343-358.

Moody WJ, Futamachi KJ, Prince DA (1974) Extracellular potassium activity during epileptogenesis. Exp Neurol 42:248-263.

Murakami M, Kashiwadani H, Kirino Y, Mori K (2005) State-dependent sensory gating in olfactory cortex. Neuron 46:285-296.

Nelson SB, Turrigiano GG (1998) Synaptic depression: a key player in the cortical balancing act. Nat Neurosci 1:539-541.

Orkand RK, Nicholls JG, Kuffler SW (1966) Effect of nerve impulses on the membrane potential of glial cells in the central nervous system of amphibia. J Neurophysiol 29:788-806.

Osinga HM, England JP (2005) Separating manifolds in slow-fast systems. In: Proceedings of the Fifth EUROMECH Nonlinear Dynamics Conference, pp 1699-1705, Eindhoven, The Netherlands.

Prince DA, Jacobs KM, Salin PA, Hoffman S, Parada I (1997) Chronic focal neocortical epileptogenesis: does disinhibition play a role? Can J Physiol Pharmacol 75:500-507.

Rinzel J (1985) Bursting oscillations in an excitable membrane model. In: Ordinary and partial differential equations (Sleeman BD, Jones D, eds). Berlin: Springer.

Rinzel J, Ermentrout B (1989) Analysis of neural excitability and oscillations. In: Methods in neuronal modeling (Koch C, Segev I, eds). Cambridge, MA: MIT.

Rinzel J, Lee YS (1987) Dissection of a model for neuronal parabolic bursting. J Math Biol 25:653-675.

Rutecki PA, Lebeda FJ, Johnston D (1985) Epileptiform activity induced by changes in extracellular potassium in hippocampus. J Neurophysiol 54:1363-1374.

Shilnikov A, Calabrese RL, Cymbalyuk G (2005) Mechanism of bistability: tonic spiking and bursting in a neuron model. Phys Rev E Stat Nonlin Soft Matter Phys 71:056214.

Steriade M (2004) Neocortical cell classes are flexible entities. Nat Rev Neurosci 5:121-134.

Steriade M, Contreras D (1998) Spike-wave complexes and fast components of cortically generated seizures. I. Role of neocortex and thalamus. J Neurophysiol 80:1439-1455.

Steriade M, McCarley R (2005) Brain control of wakefulness and sleep. New York: Kluwer-Springer.

Steriade M, McCormick DA, Sejnowski TJ (1993) Thalamocortical oscillations in the sleeping and aroused brain. Science 262:679-685.

Steriade M, Timofeev I, Grenier F (2001) Natural waking and sleep states: a view from inside neocortical neurons. J Neurophysiol 85:1969-1985.

Tasker JG, Dudek FE (1991) Electrophysiology of GABA-mediated synaptic transmission and possible roles in epilepsy. Neurochem Res 16:251-262.

Timofeev I, Grenier F, Bazhenov M, Sejnowski TJ, Steriade M (2000) Origin of slow cortical oscillations in deafferented cortical slabs. Cereb Cortex 10:1185-1199.

Timofeev I, Grenier F, Steriade M (2001) Disfacilitation and active inhibition in the neocortex during the natural sleep-wake cycle: an intracellular study. Proc Natl Acad Sci USA 98:1924-1929.

Timofeev I, Bazhenov M, Sejnowski T, Steriade M (2002) Cortical hyperpolarization-activated depolarizing current takes part in the generation of focal paroxysmal activities. Proc Natl Acad Sci USA 99:9533-9537.

Topolnik L, Steriade M, Timofeev I (2003) Hyperexcitability of intact neurons underlies acute development of trauma-related electrographic seizures in cats in vivo. Eur J Neurosci 18:486-496.

Traub RD, Borck C, Colling SB, Jefferys JG (1996) On the structure of ictal events in vitro. Epilepsia 37:879-891.

Traynelis SF, Dingledine R (1988) Potassium-induced spontaneous electrographic seizures in the rat hippocampal slice. J Neurophysiol 59:259-276.

Tsodyks MV, Markram H (1997) The neural code between neocortical pyramidal neurons depends on neurotransmitter release probability. Proc Natl Acad Sci USA 94:719-723.

Turrigiano GG, Marder E, Abbott LF (1996) Cellular short-term memory from a slow potassium conductance. J Neurophysiol 75:963-966.

Yuen GL, Hockberger PE, Houk JC (1995) Bistability in cerebellar Purkinje cell dendrites modelled with high-threshold calcium and delayed-rectifier potassium channels. Biol Cybern 73:375-388. 